Document downloaded from:

http://hdl.handle.net/10251/103234

This paper must be cited as:

Payri, R.; Gimeno, J.; Marti-Aldaravi, P.; Alarcón-Herrera, MY. (2017). A new approach to compute temperature in a liquid-gas mixture. Application to study the effect of wall nozzle temperature on a Diesel injector. International Journal of Heat and Fluid Flow. 68:79-86. doi:10.1016/j.ijheatfluidflow.2016.12.008

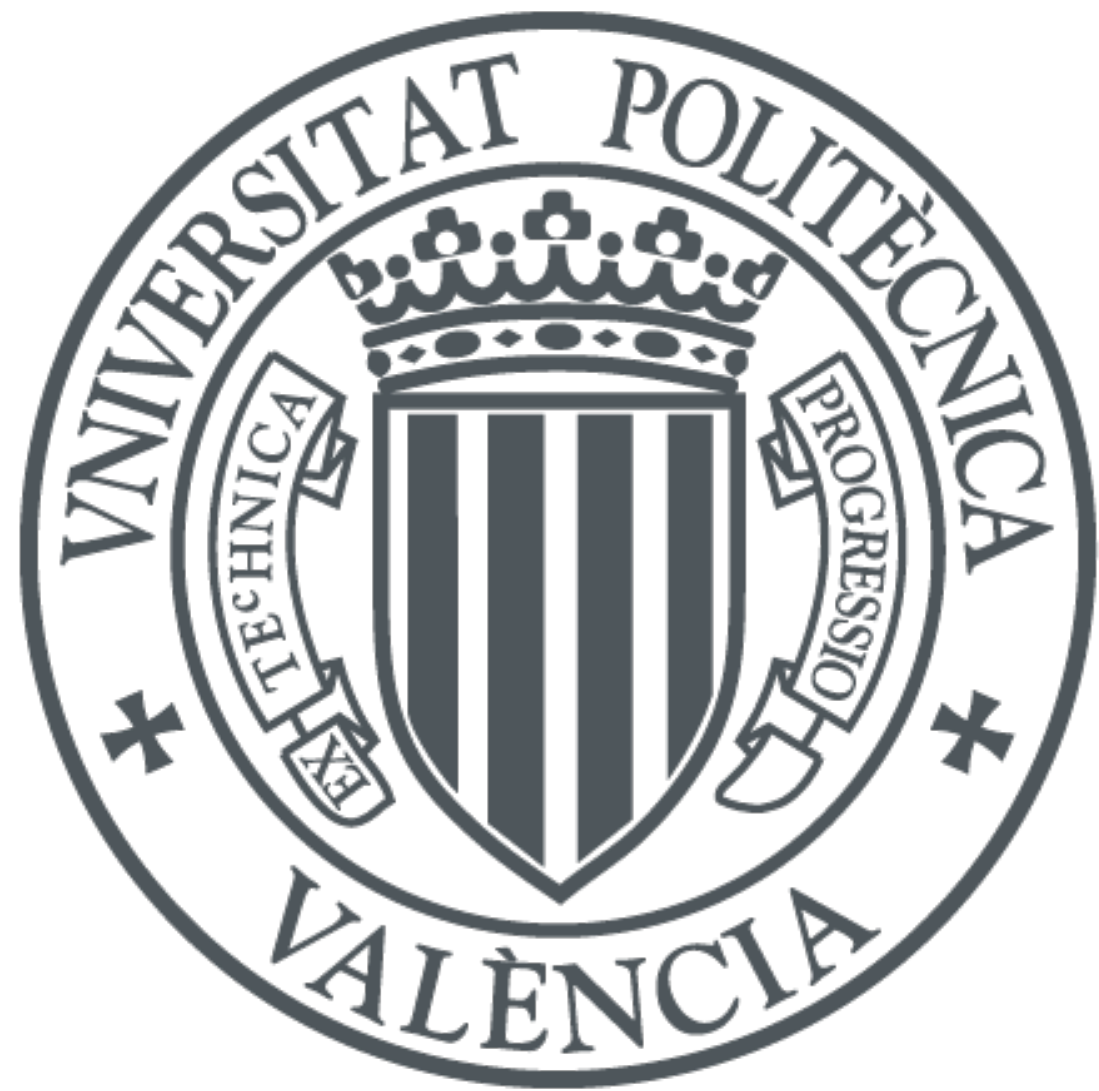

The final publication is available at

https://doi.org/10.1016/j.ijheatfluidflow.2016.12.008

Copyright Elsevier

Additional Information 


\title{
A new approach to compute temperature in a liquid-gas mixture. Application to study the effect of wall nozzle temperature on a Diesel injector
}

\author{
Raúl Payria ${ }^{\text {a Jaime Gimeno }}{ }^{\text {a }}$ Pedro Martí-Aldaravía ${ }^{a, *}$, Mary Alarcón ${ }^{a}$ \\ ${ }^{a}$ CMT - Motores Térmicos, Universitat Politècnica de València, Edificio 6D, Camino de \\ Vera s/n, 46022, Valencia, Spain. Tel. num. 0034-963877650. Fax Num. \\ $0034-963877659$
}

\begin{abstract}
Thermal effects on internal combustion engines have been always a hot topic. Concretely, temperature influence on the injection systems is still under research. In this work, a homogeneous model named Eulerian Spray Atomization (ESA) is used to simulate Engine Combustion Network (ECN) Diesel Spray A conditions. A new approach is considered for the thermodynamic model of the fuel and gas mixture. Experimentally obtained values of the liquid enthalpy are directly employed in the simulation to determine the temperature, without any need of knowing its heat capacity or expansion coefficient. This allows to accurately study heating and cooling phenomena inside the Diesel nozzle. Results show that two different boundary conditions could be applied at nozzle walls, either fixed temperature value or adiabatic walls, and still obtain good prediction of injection parameters. Also, the effect of fuel temperature has been investigated. For Spray A conditions, nozzle and spray parameters are the same regardless the fuel temperature. Nevertheless, fluid properties (density, velocity...) inside the nozzle significantly change; which means that these type of models could serve in future for cavitation erosion or coking studies.
\end{abstract}

Keywords: Diesel, Nozzle, Temperature, Boundary condition, Compressible fluid, Engine Combustion Network

\footnotetext{
*Corresponding author. E-mail: pedmar15@mot.upv.es
} 
R. Payri, J. Gimeno, P. Martí-Aldaraví, M. Alarcón. A new approach to compute temperature in a liquid-gas mixture. Application to study the effect of wall temperature on a Diesel injector, International Journal of Heat and Fluid Flow 68 (2017): 79-86, doi:10.1016/j.ijheatfluidflow.2016.12.008. Author copy

\section{Introduction}

Reduction of fuel consumption is one of the goals in research of internal combustion (IC) engines. Since few years ago, one of the strategies under investigation for IC is the increase of injection pressure [1, 2]. Under such high pressure conditions, thermal effects become a major issue [3], though they have been always a topic under investigation $[4,5]$.

Small sizes of the fluid passages and high velocity flows make the instrumentation of an injector a very difficult task. Therefore, simulations are a useful tool to study heat transfer and fuel temperature variations on injection systems, concretely inside the injector itself. In order to computationally study the thermal effects on the injection system, fuel properties need to be known in advance as function of pressure and temperature [6, 7]. Under these circumstances, the main goal of this work is to propose a new methodology to account for the thermodynamic properties of the fuel and fuel-gas mixture in simulations. This new methodology improves the prediction of local values of fluid properties such as density, velocity or temperature, whose influence on other phenomena, such as coking [8] or cavitation [9], is significant.

The new approach proposed here is employed to study the influence of fuel temperature on the flow pattern inside the injector nozzle and the nearfield behavior of the spray for non-evaporative conditions. Additionally, differences between assuming adiabatic nozzle walls and constant temperature walls (heated or cooled) are analyzed.

To do so, a model able to solve the coupling between nozzle flow and the spray would be desirable. New homogeneous Eulerian modeling $[10,11,12]$ seems to be the best approach. From those, the only one that, until now, has demonstrated to deal seamlessly with nozzle flow and spray is the Eulerian Spray Atomization (ESA) model [13, 14, 15].

In order to validate the simulations performed with the new thermodynamic model, it is important to have extensive and high quality experimental data. The Engine Combustion Network (ECN) [16] is an international collaboration between research institutes and universities that addresses the study of fuel injection with reliable standards. That is why their condition called "Spray A" has been taken as a reference. It consists of a single-hole nozzle aligned with the injector axis employed for research purposes. Also the injection conditions (given in next sections) are representative of actual engine conditions in normal car operation. A single component representative of Diesel fuel such as n-Dodecane (whose thermodynamic properties are 
R. Payri, J. Gimeno, P. Martí-Aldaraví, M. Alarcón. A new approach to compute temperature in a liquid-gas mixture. Application to study the effect of wall temperature on a Diesel injector, International Journal of Heat and Fluid Flow 68 (2017): 79-86, doi:10.1016/j.ijheatfluidflow.2016.12.008. Author copy

well known [17]) is selected for standard fuel used by ECN collaborators to perform both experiments and simulations.

This paper is divided in four sections. Additional to this brief Introduction section, in Section 2 the basis of the thermal and computational modeling are explained, together with the configuration of the simulations. The following Section 3 shows the results obtained and their analysis. And the final Section 4 summarizes the main findings of the this investigation.

\section{Methodology}

\subsection{Theoretical background}

Pressurized fuel inside the injector is accelerated within the nozzle, converting its flow work into velocity, in other words, into kinetic energy. During this expansion operation, the temperature of the fluid decreases together with its pressure. And as always, there are some losses in the process, for instance, the flow encounters wall friction in its path. One can assume that those energy losses are converted into heat, which increases the fuel temperature. Since the total energy (sum of the flow work, internal energy and kinetic energy -turbulent kinetic energy is neglected-) is known at the beginning and ending of the process, it is possible to estimate the temperature change as function of the losses [9], in this case measured with the velocity coefficient, $C_{v}[19]$.

Figure 1 represents a Diesel nozzle, where the liquid fuel flows from the inlet (1) to the outlet (2). Inlet conditions (pressure, temperature and velocity -which is approximately zero-) are known, whilst at the outlet just the pressure is known (back pressure).

As it is explained later in this section, the enthalpy of the liquid fuel can be expressed as function of two thermodynamic variables such as pressure $(p)$ and entropy $(S), h_{l}(p, S)$. In the same way, the entropy is function of pressure $(p)$ and temperature $(T)$. These relationships can be easily found in the literature [17]. Therefore, enthalpy and entropy at inlet are known. If the process is assumed to be adiabatic, and also isentropic, the theoretical exit velocity $U_{2}$ can be calculated using Equation 1.

$$
h_{0}=\text { constant } \rightarrow h_{l, 2}\left(p_{1}, T_{1}\right)=h_{l, 2}\left(p_{2}, T_{2}\right)+\frac{U_{2}^{2}}{2}
$$

For a given value of losses, the effective velocity is calculated from the definition of the velocity coefficient: 
R. Payri, J. Gimeno, P. Martí-Aldaraví, M. Alarcón. A new approach to compute temperature in a liquid-gas mixture. Application to study the effect of wall temperature on a Diesel injector, International Journal of Heat and Fluid Flow 68 (2017): 79-86, doi:10.1016/j.ijheatfluidflow.2016.12.008. Author copy

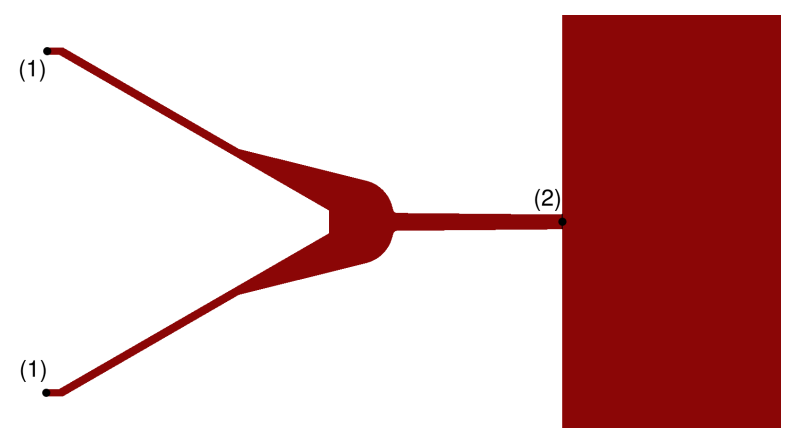

Figure 1: Sketch of a single-hole Diesel nozzle.

$$
U_{\text {eff }}=C_{v} \sqrt{\frac{2\left(p_{i}-p_{b}\right)}{\rho_{l}}}
$$

Equation 1 can be re-written to obtain the real enthalpy at the outlet section, and from this value, the temperature of the fuel at this section can be obtained.

$$
h_{l, 2}\left(p_{2}, T_{2}\right)=h_{l, 2}\left(p_{1}, T_{1}\right)-\frac{U_{e f f}^{2}}{2}
$$

The relationship between losses and inlet-outlet temperature difference is shown in Figure 2 for ECN Spray A injection conditions (see Section 2.4). As previously shown by Theodorakakos et al. [9], who carried out a similar analysis, despite the fuel depressurization, temperature increases, particularly for the partial needle opening case with low values of $C_{v}$. In this plot, the value of $C_{v}=0$ corresponds to the iso-enthalpy process where the potential energy of the flow is transformed into thermal energy. And the maximum value of $C_{v}$ corresponds to the isentropic process, where the potential energy is transformed into kinetic energy without losses.

The experimental steady state value of $C_{v}=0.92$ [18] is marked in Figure 2 with a dashed line. For that value, a temperature drop of $12.2 \mathrm{~K}$ is expected according to this simplified zero-dimensional model.

\subsection{Calculation of mixture enthalpy}

Homogeneous Eulerian models are based on the definition of the liquid mass fraction, $Y$ (see Section 2.3). All thermo-physical properties of the 
R. Payri, J. Gimeno, P. Martí-Aldaraví, M. Alarcón. A new approach to compute temperature in a liquid-gas mixture. Application to study the effect of wall temperature on a Diesel injector, International Journal of Heat and Fluid Flow 68 (2017): 79-86, doi:10.1016/j.ijheatfluidflow.2016.12.008. Author copy

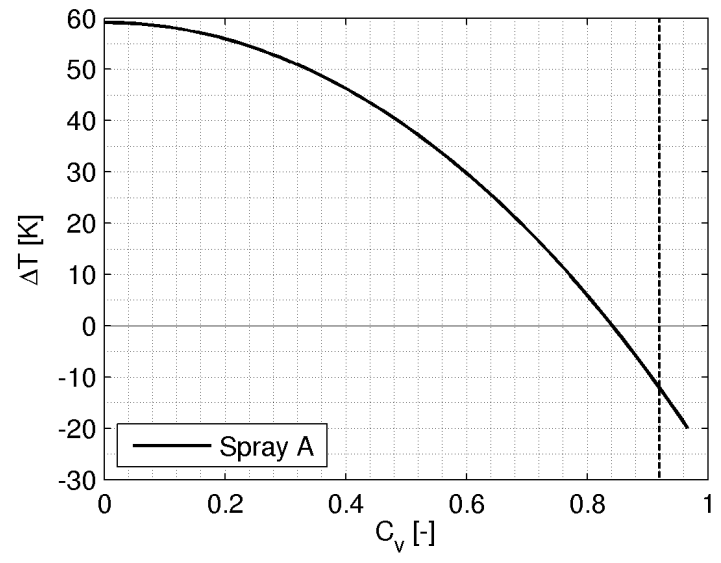

Figure 2: n-Dodecane temperature change as function of the velocity coefficient (losses) for ECN injection conditions, $p_{i}=150 \mathrm{MPa}$ and $p_{b}=2 \mathrm{MPa}$.

mixture can be computed from this quantity. Concretely, the enthalpy of the mixture, $h$, with Equation 3.

$$
d h=Y d h_{l}+(1-Y) d h_{g}
$$

The enthalpy is transported following the balance Equation 4 ; where $K$ is the mean kinetic energy $K=1 / 2 \boldsymbol{U}^{2}=1 / 2\left(u_{x}^{2}+u_{y}^{2}+u_{z}^{2}\right) ; \kappa_{\text {eff }}$ is the effective thermal diffusivity, which takes into account also turbulence; and $\boldsymbol{\tau} \cdot \nabla \boldsymbol{U}$ is the viscous dissipation calculated as seen in Equation 5, which may play a significant role inside Diesel nozzles due to large velocity gradients found near orifice walls.

$$
\begin{array}{r}
\frac{\partial(\rho h)}{\partial t}+\nabla(\rho \boldsymbol{U} h)-\nabla\left(\kappa_{\text {eff }} \nabla h\right)=\frac{\partial p}{\partial t}-\frac{\partial K}{\partial t}-\nabla(\rho \boldsymbol{U} K)+\boldsymbol{\tau} \cdot \nabla \boldsymbol{U} \\
\boldsymbol{\tau} \cdot \nabla \boldsymbol{U}=2 \mu\left[\left(\frac{\partial u_{x}}{\partial x}\right)^{2}+\left(\frac{\partial u_{y}}{\partial y}\right)^{2}+\left(\frac{\partial u_{z}}{\partial z}\right)^{2}-\frac{1}{3}(\nabla \boldsymbol{U})^{2}\right]+ \\
+\mu\left[\frac{\partial u_{y}}{\partial x}+\frac{\partial u_{x}}{\partial y}\right]^{2}+\mu\left[\frac{\partial u_{z}}{\partial y}+\frac{\partial u_{y}}{\partial z}\right]^{2}+\mu\left[\frac{\partial u_{x}}{\partial z}+\frac{\partial u_{z}}{\partial x}\right]^{2}
\end{array}
$$


R. Payri, J. Gimeno, P. Martí-Aldaraví, M. Alarcón. A new approach to compute temperature in a liquid-gas mixture. Application to study the effect of wall temperature on a Diesel injector, International Journal of Heat and Fluid Flow 68 (2017): 79-86, doi:10.1016/j.ijheatfluidflow.2016.12.008. Author copy

In order to obtain the temperature from the energy (enthalpy in this case), some homogeneous models [21] employ an equivalent specific heat capacity, $C_{p}=Y C_{p, l}+(1-Y) C_{p, g}$, where $C_{p, l}$ and $C_{p, g}$ denote the specific heats at constant pressure of the liquid and gas respectively; which both are assumed to be constant. Then, they use Equation 6 .

$$
h=C_{p} T
$$

Others [12] take into account the variation of the liquid specific heat with the temperature through out a Rowlinson-Bondi equation [22]. Those approximations work well for simulating sprays, where variations of pressure are small. However, pressure gradients inside Diesel injector nozzles are quite large and change liquid properties, and so the injector performance [23]. Therefore, the enthalpy must be generally expressed as defined in Equation 7, where $\alpha$ represents the coefficient of thermal expansion.

$$
d h=C_{p} d T+(1-\alpha T) \frac{d p}{\rho}
$$

Notice that for an ideal gas, $\alpha=1 / T$, and for perfect gases the heat capacity is constant [24]. Therefore, for gas phases the relationship between enthalpy and temperature is straightforward (Equation 6). That is not the case of the liquid phase, where both $C_{p, l}$ and $\alpha_{l}$ are function of pressure and temperature; and can be experimentally determined [17]. Thus, the liquid enthalpy can be expressed as function of the thermodynamic variables pressure and temperature.

The direct use of Equation 7 in a Computational Fluid Dynamics (CFD) solver increases the number of differential equations to be solved (increase computational cost) and hinder the pressure-velocity coupling. Instead, a polynomial expression is fitted to experimental data of n-Dodecane [17, 7], resulting in Equation 8, which at the same time is represented in Figure 3. The agreement between the polynomial expression and the experimental data is quite good $\left(R^{2}=0.999983\right)$. This approach simplifies the thermodynamic model of the fuel without loss of accuracy within the range of available experimental data.

$$
\begin{aligned}
h_{l}(p, T)= & 2206.46(T-298)+1.8352(T-298)^{2} \\
& +9.398410^{-4}\left(p-10^{5}\right)+0.640110^{-12}\left(p-10^{5}\right)^{2} \\
& -0.510710^{-6}\left(p-10^{5}\right)(T-298)
\end{aligned}
$$


R. Payri, J. Gimeno, P. Martí-Aldaraví, M. Alarcón. A new approach to compute temperature in a liquid-gas mixture. Application to study the effect of wall temperature on a Diesel injector, International Journal of Heat and Fluid Flow 68 (2017): 79-86, doi:10.1016/j.ijheatfluidflow.2016.12.008. Author copy

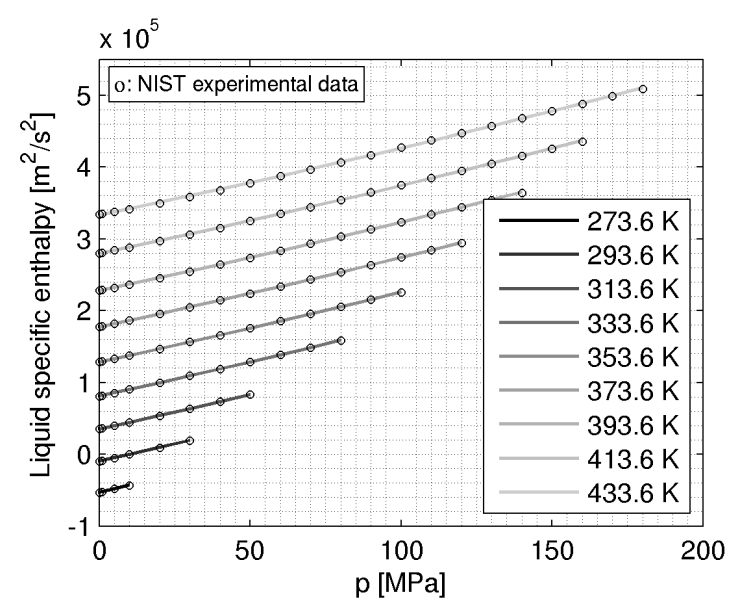

Figure 3: n-Dodecane specific enthalpy as function of pressure and temperature.

At the end, in the CFD solver used in this study, the enthalpy is computed with the energy transport equation (Equation 4), and then the temperature is obtained by numerically solving Equation 9 .

$$
h=Y h_{l}(p, T)+(1-Y) C_{p, g} T
$$

\subsection{Description of the model}

A multi-phase model is required to simulate the Diesel spray under nonevaporative conditions. In this case, an Eulerian homogeneous model is employed in order to be able to study the nozzle flow and the spray at the same time. The model is called Eulerian Spray Atomization (ESA) and has been described and validated in previous works $[13,14,15]$. It is based on the one developed by Vallet et al. [10], which assumes four basic principles: high Reynolds and Weber numbers, small difference in velocity between phases, the dispersion is calculated through a balance equation, and the mean size of liquid fragments can be obtained from the mean surface area of the liquid-gas interface per unit volume. Nevertheless, there is not droplet size experimental data for the selected injection conditions to compare with yet, so droplet size results are not shown in the present work. Consistently, description of the droplet size modeling has been omitted and the interested reader is referred to the work of Vallet et al. [10].

The dispersion of the liquid into the gaseous ambient is modeled with a turbulent diffusion flux given by Fick's law. The transport equation of 
R. Payri, J. Gimeno, P. Martí-Aldaraví, M. Alarcón. A new approach to compute temperature in a liquid-gas mixture. Application to study the effect of wall temperature on a Diesel injector, International Journal of Heat and Fluid Flow 68 (2017): 79-86, doi:10.1016/j.ijheatfluidflow.2016.12.008. Author copy.

the liquid mass fraction is Equation 10, where $D_{Y, \text { eff }}$ is the diffusivity coefficient computed as in Equation 11, being $S c$ the Schmidt number. By the Kolmogorov hypothesis for small scale features of the flow, $S c=1$ can be assumed.

$$
\begin{gathered}
\frac{\partial(\rho Y)}{\partial t}+\nabla \cdot(\rho \boldsymbol{U} Y)-\nabla\left(D_{Y, e f f} \nabla Y\right)=0 \\
D_{Y, \text { eff }}=\frac{\mu_{t}}{S c}
\end{gathered}
$$

A turbulence model is necessary to estimate the turbulent viscosity, $\mu_{t}$. In this case a Reynolds-Averaged Navier-Stokes (RANS) 2-equations viscosity model is selected, concretely the SST k- $\omega$. It has been proved that it is able to correctly predict the flow inside the nozzle and along the spray [13].

Once the liquid mass fraction is obtained, the density of the liquid-gas mixture is given by an equation of state such as Equation 12. Nitrogen is used for the gas phase, which is assumed to behave as an ideal and perfect gas under the range of pressures and temperatures tested.

$$
\rho=\frac{1}{\frac{Y}{\rho_{l}}+\frac{1-Y}{\rho_{g}}}
$$

The liquid phase (the fuel) is n-Dodecane as discussed in the Introduccion section. Khasanshin et al. [17] measured also its density and bulk modulus as function of pressure and temperature. The methodology developed by [7] was used to fit polynomial expressions to both the density (Equation 13) and the compressibility (Equation 14) of the liquid. The same was done for the liquid specific enthalpy (Equation 8).

$$
\begin{aligned}
\rho_{l}= & 744.83-0.7079(T-298)+0.732410^{-6}\left(p-10^{5}\right) \\
& -2.07410^{-15}\left(p-10^{5}\right)+0.107810^{-3}(T-298)^{2} \\
& +0.00222710^{-6}\left(p-10^{5}\right)(T-298)
\end{aligned}
$$


R. Payri, J. Gimeno, P. Martí-Aldaraví, M. Alarcón. A new approach to compute temperature in a liquid-gas mixture. Application to study the effect of wall temperature on a Diesel injector, International Journal of Heat and Fluid Flow 68 (2017): 79-86, doi:10.1016/j.ijheatfluidflow.2016.12.008. Author copy.

The rest of balance equations (continuity, momentum, energy -Equation 4and pressure) are the common ones used in compressible single-phase solvers and can be easily found in the literature, e.g. the work of Weller et al. [25].

OpenFOAM 2.3.0 $\AA$ is the finite volume CFD software selected for this study because it is open source, so new solvers are easy to develop and test. Transport equations are solved within a PIMPLE (combination of Pressure Implicit with Splitting Operators -PISO- and Semi-Implicit Method for Pressure-Linked Equations -SIMPLE-) loop, which increases computational cost but ensures stability and accuracy. First order spatial upwind discretization and linear interpolation schemes are used, with an Euler scheme for the time discretization. PBiCG (Preconditioned Bi-Conjugate Gradient) solver with DILU (Diagonal Incomplete LU) preconditioner is used for all variables except for the pressure, which is solved with a PCG (Preconditioned Conjugate Gradient) solver with DIC (Diagonal Incomplete Cholesky) preconditioner. A relaxation factor of 0.3 is used for the pressure, whereas a value of 0.7 is used for the rest of variables except for the density, which is solved without relaxation.

\subsection{Case set-up}

The case set-up is similar to the one employed by the authors in other recent works [26]. ECN Spray A conditions [16, 18] are simulated. That is, a Bosch solenoid-activated injector with an axial single-hole nozzle is employed. The nominal orifice outlet diameter is $0.090 \mathrm{~mm}$, with a k-factor 1.5 and a fillet inlet radius of $0.025 \mathrm{~mm}$. The Spray A nozzle was designed to avoid cavitation to occur. The reference injection conditions for comparison with experiments [18] correspond to an injection of pressure of $150 \mathrm{MPa}$ and ambient density of $22.8 \mathrm{~kg} / \mathrm{m}^{3}$. The ambient gas is at room temperature of $303 \mathrm{~K}$. The fuel temperature is set to $343 \mathrm{~K}$ in the reference, but it is varied from 263 to $363 \mathrm{~K}$ for this study.

When fuel temperature is varied, not only the thermodynamic properties change, also dynamic properties such as viscosity. Liquid phase n-Dodecane viscosity strongly depends on temperature and also on pressure [27]. However, the dynamic properties model of the ESA solver, as many other solvers, assumes constant kinematic viscosity. Thus, local variations of viscosity due to variations in pressure and in temperature cannot be considered. Nonetheless, kinematic viscosity value is modified for each simulation following Caudwell et al. [27] results, considering constant reference pressure equal to the discharge pressure of $2 \mathrm{MPa}$. 
R. Payri, J. Gimeno, P. Martí-Aldaraví, M. Alarcón. A new approach to compute temperature in a liquid-gas mixture. Application to study the effect of wall temperature on a Diesel injector, International Journal of Heat and Fluid Flow 68 (2017): 79-86, doi:10.1016/j.ijheatfluidflow.2016.12.008. Author copy.

Figure 4 shows the domain and the mesh employed for the simulations. Although Spray A nozzle orifice has a small eccentricity [18], its effect on nozzle flow and spray evolution is small [14] and it is neglected in this study. Thus, a wedge two-dimensional domain is used. The mesh has 67402 elements, enough to ensure mesh independent results, with 18 elements covering the orifice outlet radii.

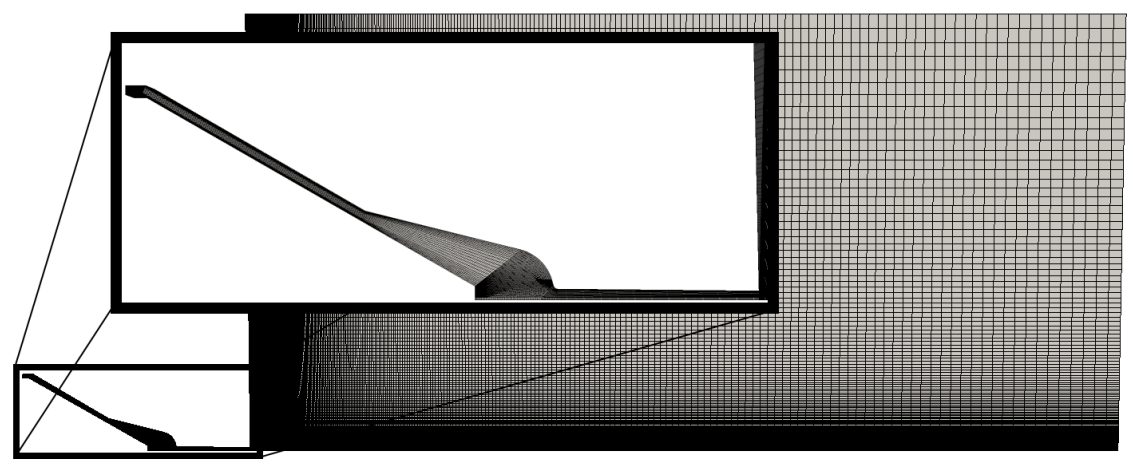

Figure 4: Computational domain and mesh.

The inlet of the nozzle is represented with a time-varying pressure condition and constant temperature. The time resolved value of the pressure is obtained from the experiments [18]. The turbulent intensity at the inlet is equal to $5 \%$ of the mean velocity and the turbulent integral length scale is $10 \%$ of the orifice outlet diameter. The outlet of the domain, on the right hand end, is a non-reflective or wave transmissive boundary condition, with a pressure value that gives an ambient density of $22.8 \mathrm{~kg} / \mathrm{m}^{3}$. The rest of the boundaries are non-slip walls. For walls that form the nozzle, two types of boundary conditions are used for the temperature. The first one is a fixed temperature value, allowing heat flux through the wall. The second one is known as zero gradient, and corresponds to adiabatic walls. Standard wall functions for resolving the boundary layer next to the walls are also used.

\section{Results and discussion}

\subsection{Isothermal vs. adiabatic walls}

In this first section of the results, two simulations at Spray A reference conditions are compared, one performed with nozzle walls at fixed temperature of $343 \mathrm{~K}$, and the other one with adiabatic walls but the fuel inside 
R. Payri, J. Gimeno, P. Martí-Aldaraví, M. Alarcón. A new approach to compute temperature in a liquid-gas mixture Application to study the effect of wall temperature on a Diesel injector, International Journal of Heat and Fluid Flow 68 (2017): 79-86, doi:10.1016/j.ijheatfluidflow.2016.12.008. Author copy

the nozzle at temperature of $343 \mathrm{~K}$. In both cases, the initial temperature of the fuel is also $343 \mathrm{~K}$. Experimental data [16, 18, 28], when available, is also compared to simulation results.

Table 1 in next subsection shows discharge coefficient, $C_{d}$, velocity coefficient, $C_{v}$, and area coefficient, $C_{a}$, as defined by Payri et al. [19]. As shown in previous works $[13,14,15]$ the ESA solver is able to accurately reproduce experimental values. When comparing simulations with adiabatic walls and constant temperature walls, no difference is found. This means that differences in nozzle flow between these two simulations are going to be small.

In order to further investigate nozzle flow differences between these two simulations, velocity and temperature profiles along the nozzle axis are plotted in Figure 5 starting from the needle position $x=-1.4094 \mathrm{~mm}$. They are also plotted orifice outlet section in Figure 6 (the step-shaped curves in this figure are related to mesh resolution and interpolation scheme). In Figure 5 (and some other of the following) the vertical dashed line marks the position of the orifice outlet. Differences between simulations in temperature are around 1-2 K, even inside the boundary layer where viscous heating takes place. This has negligible effect on density, and so, on velocity, as noted in the figures.

Figure 5 shows the core flow properties inside the nozzle. Inside the sac, there is almost stagnated flow (low velocity) at constant temperature established by wall temperature and initial conditions. Large and fast acceleration occurs at the orifice inlet section, which is coupled to a sudden decrease in temperature due to expansion. Inside the orifice, the flow accelerates and cools down as the section decreases down to outlet diameter. After exiting the nozzle, velocity and temperature are kept constant a few millimeters inside the intact core length [14]. It is interesting to see how the ESA model is able to reproduce the temperature drop predicted by the zero-dimensional model presented in Section 2. According to the simulation (Figure 5(b)), the temperature drop is $18.7 \mathrm{~K}$, not far from the value of $19.9 \mathrm{~K}$ predicted by the zero-dimensional model for the isentropic case (maximum $C_{v}$ ), especially taking into account that this model does not consider friction losses. The velocity in the core flow (Figure $5(\mathrm{a})$ ) is about $620 \mathrm{~m} / \mathrm{s}$, quite similar to the isentropic exit velocity $U_{2}=619.0 \mathrm{~m} / \mathrm{s}$ predicted by the zero-dimensional model. Therefore, according to these simulation results, the core flow can be assumed to be isentropic.

The temperature increase inside the boundary layer due to viscous heat- 
R. Payri, J. Gimeno, P. Martí-Aldaraví, M. Alarcón. A new approach to compute temperature in a liquid-gas mixture. Application to study the effect of wall temperature on a Diesel injector, International Journal of Heat and Fluid Flow 68 (2017): 79-86, doi:10.1016/j.ijheatfluidflow.2016.12.008. Author copy

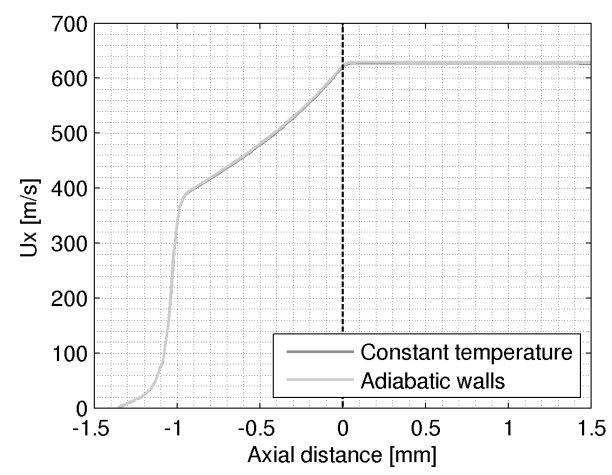

(a) Velocity.

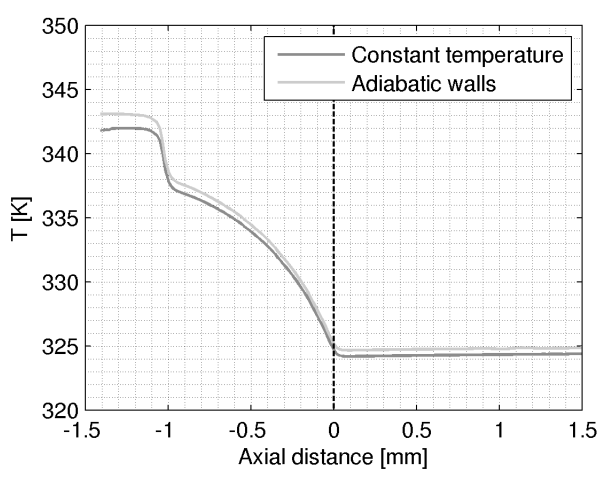

(b) Temperature.

Figure 5: Profiles along the nozzle axis at time $0.5 \mathrm{~ms}$ after start of injection for different wall boundary conditions.

ing, shown in Figure 6(b), is about $70 \mathrm{~K}$. The consequent decrease in fuel density is significant and this may affect the boundary layer development. Although RANS approach is not very accurate because it does not consider all modulations of turbulence [29] and typically leads to under-estimation of area coefficient, the fact that the area coefficient is well predicted by the simulations means that the size of boundary layer and fluid properties inside it are close to reality. Therefore, including viscous heating helps simulations to accurately reproduce experiments.

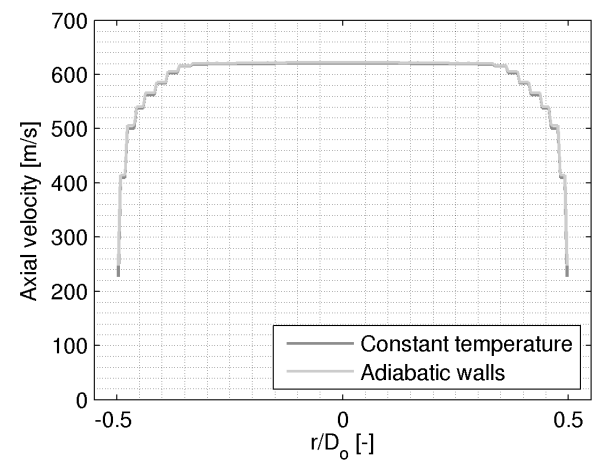

(a) Velocity.

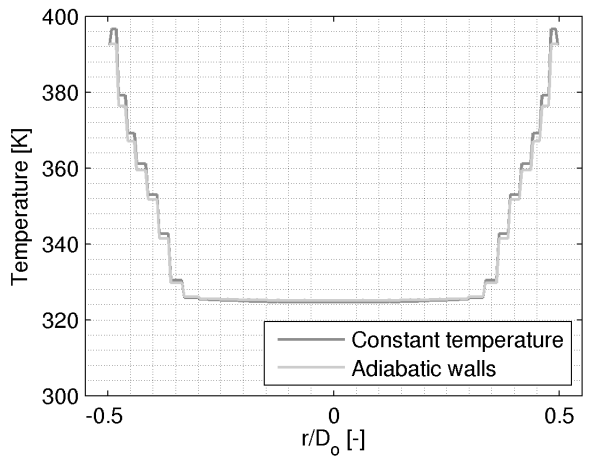

(b) Temperature.

Figure 6: Profiles along the orifice outlet at time $0.5 \mathrm{~ms}$ after start of injection for different wall boundary conditions. 
R. Payri, J. Gimeno, P. Martí-Aldaraví, M. Alarcón. A new approach to compute temperature in a liquid-gas mixture. Application to study the effect of wall temperature on a Diesel injector, International Journal of Heat and Fluid Flow 68 (2017): 79-86, doi:10.1016/j.ijheatfluidflow.2016.12.008. Author copy

Mass weighted average value of temperature at orifice exit section is $340.8 \mathrm{~K}$, which represents a drop of only $2.2 \mathrm{~K}$ from inlet temperature, whilst zero-dimensional model predicts a drop of $12.2 \mathrm{~K}$. There are two possible explanations for such large difference. The first one is that the temperature field requires longer times to reach steady state conditions. However, by analyzing time evolution of average exit temperature, it is observed that this value remains almost constant for the full duration of the simulation. The second explanation is that the model is over-estimating the width of the thermal boundary layer. In that case, re-formulation of the sub-model that computes the effective thermal diffusivity $\kappa_{\text {eff }}$ is required.

From the comparison performed in this subsection, it can be concluded that no significant difference is obtained if adiabatic wall boundary condition is used instead of a temperature fixed value condition. This is in accordance with the experimental results obtained by F. J. Salvador et al. [30] for high Reynolds number cases. If the temperature value at nozzle walls is unknown, the use of adiabatic walls is recommended, thus, unrealistic heat exchange in the simulations is avoided. However, if the injector nozzle in the engine or the experiments is cooled (kept at constant temperature), the fixed value condition could be used, and then wall temperature can be set to a value different than fuel temperature, so the heat transfer can be modeled.

\subsection{Variation of wall and fuel temperature}

Influence of fuel temperature on injection parameters is analyzed in this second subsection. As commented in Section 2.4, the fuel temperature is varied from 263 to $363 \mathrm{~K}$. When this type of study is performed experimentally, the injector nozzle would be cooled to the desired temperature [5]. To mimic those conditions with the simulations, constant wall temperature is used as wall boundary condition for these simulations. The initial fuel temperature is equal to the wall temperature. The effects of fuel temperature on the injector dynamics and nozzle flow from the experimental point of view have already been reported in the literature [5]. In that work, Salvador et al. observed a decrease in the discharge coefficient as they reduced the fuel temperature. Those variations were smaller (almost irrelevant) for medium to high injection pressures. They associated the decrease in discharge coefficient to a wider boundary layer inside the orifice that reduced the effective area and velocity. In the present work, Reynolds numbers obtained for lowest temperatures are close to critical Reynolds number where the boundary layer transition to turbulent and the discharge coefficient turns constant [31]. 
R. Payri, J. Gimeno, P. Martí-Aldaraví, M. Alarcón. A new approach to compute temperature in a liquid-gas mixture. Application to study the effect of wall temperature on a Diesel injector, International Journal of Heat and Fluid Flow 68 (2017): 79-86, doi:10.1016/j.ijheatfluidflow.2016.12.008. Author copy

\begin{tabular}{ccccccc}
\hline \hline & $\boldsymbol{C}_{\boldsymbol{d}}$ & $\boldsymbol{C}_{\boldsymbol{v}}$ & $\boldsymbol{C}_{\boldsymbol{a}}$ & $\boldsymbol{R e}[-]$ & $\boldsymbol{\rho}_{\boldsymbol{g}} / \boldsymbol{\rho}_{\boldsymbol{f}}[-]$ & $\boldsymbol{O} \boldsymbol{h}[-]$ \\
\hline Experimental & 0.90 & 0.92 & 0.98 & 58131 & 0.0312 & 0.0166 \\
Adiabatic & 0.90 & 0.92 & 0.98 & 58131 & 0.0312 & 0.0166 \\
$\boldsymbol{T}=\mathbf{2 6 3} \mathbf{K}$ & 0.90 & 0.92 & 0.98 & 18818 & 0.0291 & 0.0513 \\
$\boldsymbol{T}=\mathbf{2 7 3} \mathbf{K}$ & 0.91 & 0.92 & 0.98 & 18717 & 0.0294 & 0.0516 \\
$\boldsymbol{T}=\mathbf{3 0 3} \mathbf{K}$ & 0.89 & 0.91 & 0.98 & 33630 & 0.0301 & 0.0287 \\
$\boldsymbol{T}=\mathbf{3 2 3} \mathbf{K}$ & 0.89 & 0.91 & 0.98 & 45285 & 0.0307 & 0.0213 \\
$\boldsymbol{T}=\mathbf{3 4 3} \mathbf{K}$ & 0.90 & 0.92 & 0.98 & 58131 & 0.0312 & 0.0166 \\
$\boldsymbol{T}=\mathbf{3 6 3} \mathbf{K}$ & 0.90 & 0.91 & 0.98 & 72099 & 0.0318 & 0.0134 \\
\hline \hline
\end{tabular}

Table 1: Non-dimensional coefficients that characterize nozzle flow and atomization regime for different wall and initial fuel temperatures. Experimental data and simulation with adiabatic walls are also included.

Simulations predict negligible variation in the discharge, velocity and area coefficients, as shown in Table 1; even for the lowest temperature, where the molecular viscosity is in the same order of magnitude than the turbulent viscosity. This is in accordance with experiments performed at high injection pressure, especially taking into account that n-Dodecane fuel is less viscous than the standard winter fuel used by Salvador et al. [5].

Same value of area coefficient in all cases leads to the conclusion (under non-cavitating conditions) that the width of the boundary layer is the same in all cases. This is also shown in Figure 7(a), where the axial velocity profile along the orifice outlet is depicted. The width of the boundary layer is $\delta_{99}=12.039 \mu \mathrm{m}$, which represents $26.75 \%$ of the exit diameter. As stated in previous sub-section, this value should be close to reality although RANS methods for turbulence tend to over-estimate the size of the boundary layer inside Diesel injector nozzles [32]. This has been achieved by, first, a good selection of turbulence model [13], and second, the inclusion of viscous heating.

A small increase in exit velocity as fuel temperature rises is also observed in Figure 7(a). According to Bernoulli's equation, this is a direct effect of a decrease in density, shown in Figure 7(b). However, the injection velocity is not the only parameter that defines spray atomization and mixing phenomena. Atomization regime can be determined by the density ratio $\rho_{g} / \rho_{f}$, the Reynolds number and either Ohnesorge or Weber number [33]. These three parameters are shown in Table 1. The fuel density at orifice outlet is 
R. Payri, J. Gimeno, P. Martí-Aldaraví, M. Alarcón. A new approach to compute temperature in a liquid-gas mixture. Application to study the effect of wall temperature on a Diesel injector, International Journal of Heat and Fluid Flow 68 (2017): 79-86, doi:10.1016/j.ijheatfluidflow.2016.12.008. Author copy

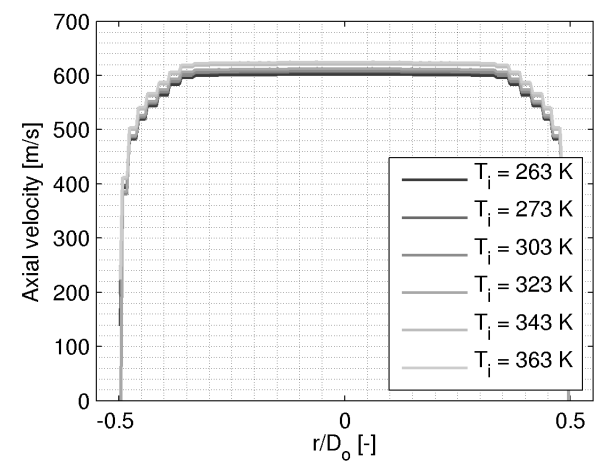

(a) Velocity at orifice exit.

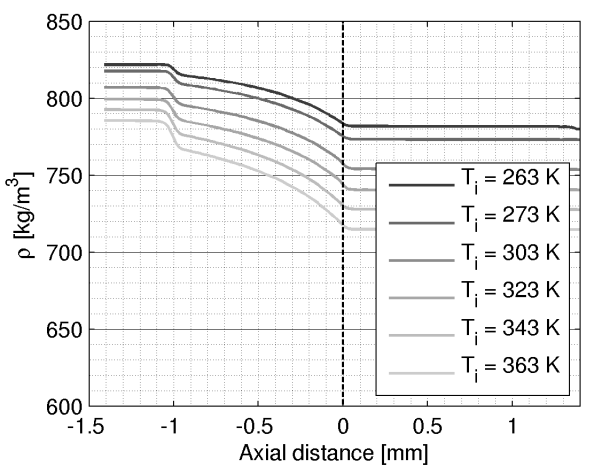

(b) Density along the axis.

Figure 7: Profiles of velocity and density at time $0.5 \mathrm{~ms}$ after start of injection for different wall and fuel temperature values.

used to compute these numbers. Though ranges of Reynolds and Ohnesorge number are wide, all values fall into complete atomization regime. Thus, small differences are expected in spray behavior.

For example, Figure 8 shows the spray penetration defined as the maximum axial distance where the liquid mass fraction is higher than $0.1 \%$ [16]. Experimental value is also shown [34]. Once again, the ESA solver is capable to predict experimental values. About the influence of fuel temperature, all penetration curves collapse, so it is negligible as expected. The spray penetration depends, among other parameters, on spray momentum, which is constant regardless the variation of fuel temperature. As the temperature increases, the liquid fuel density decreases but the injection velocity increases in the proportion that the momentum is kept almost constant [35].

In order to take a deeper look on how the fuel distributes inside the vessel, liquid volume fraction contours are displayed in Figure 9. In these kind of plots, the dense part of the spray can be clearly distinguished. The intact core in all cases is similar: width comparable to the orifice outlet diameter, and length of about $2.0-2.1 \mathrm{~mm}$, slightly growing with the increase in fuel temperature. The intact core length has been computed following criteria presented by Desantes et at. [14]. 
R. Payri, J. Gimeno, P. Martí-Aldaraví, M. Alarcón. A new approach to compute temperature in a liquid-gas mixture. Application to study the effect of wall temperature on a Diesel injector, International Journal of Heat and Fluid Flow 68 (2017): 79-86, doi:10.1016/j.ijheatfluidflow.2016.12.008. Author copy

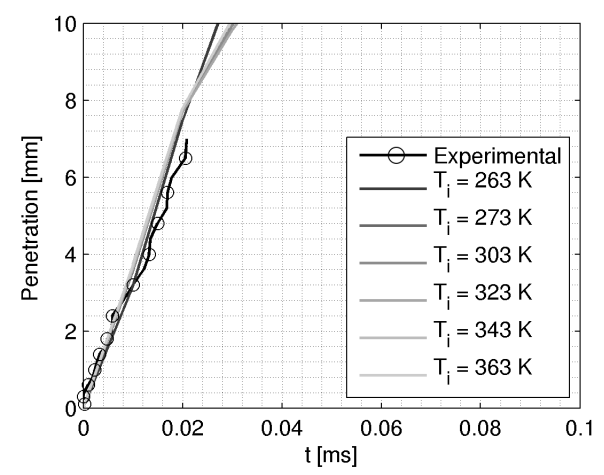

Figure 8: Spray penetration in the near-field for different wall and fuel temperature values.

\section{Conclusions}

This paper investigates the effect of fuel temperature on some injection parameters that characterize the nozzle flow and the near-field spray. To do so, a homogeneous Eulerian model, called Eulerian Spray Atomization (ESA) model, is used. The thermodynamic sub-model employed in this code allows to consider not only viscous heating, but also heating of the fuel due to pressure losses and cooling effects due to expansion that occurs inside the nozzle. This has been achieved by considering the internal energy of the fuel, concretely, the enthalpy as function of local pressure and temperature values. The relationship between these three variables has been obtained from the literature.

ECN Spray A conditions have been used as a reference due to the wide experimental information that is available. Simulation case set-up is similar to the one used in previous works. For these conditions, two different studies have been carried out. The first one analyzes the differences between using fixed temperature or adiabatic condition at nozzle walls. According to the results obtained, there is no difference between these two boundary conditions, any of them can be used and lead to the same nozzle parameters and flow variables such as velocity or temperature. This is in accordance with the literature. Nevertheless, adiabatic condition is recommended in the case the nozzle wall temperature is not exactly known.

The second study evaluates the influence of fuel temperature, which has been varied from 263 to $363 \mathrm{~K}$. Results show that nozzle parameters, such as discharge coefficient, are almost the same in all cases. Fluid properties, 
R. Payri, J. Gimeno, P. Martí-Aldaraví, M. Alarcón. A new approach to compute temperature in a liquid-gas mixture. Application to study the effect of wall temperature on a Diesel injector, International Journal of Heat and

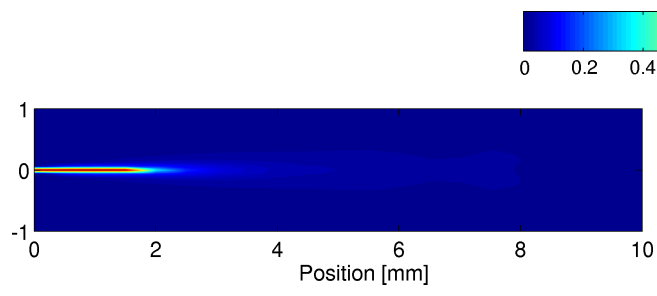

(a) $T=263 \mathrm{~K}$

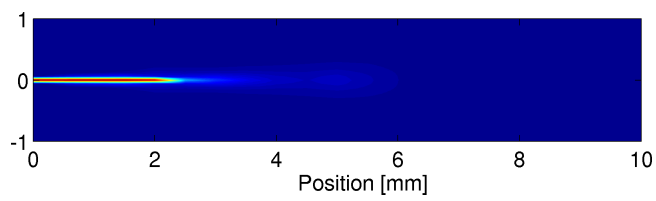

(c) $T=303 \mathrm{~K}$.

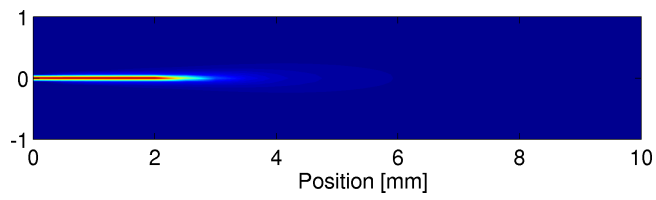

(e) $T=343 \mathrm{~K}$.

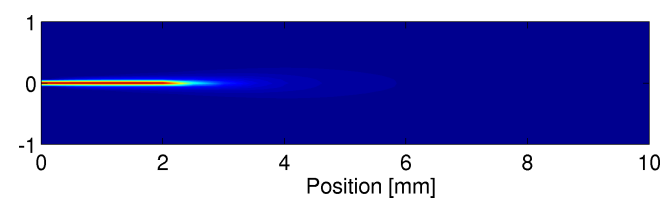

(b) $T=273 \mathrm{~K}$.

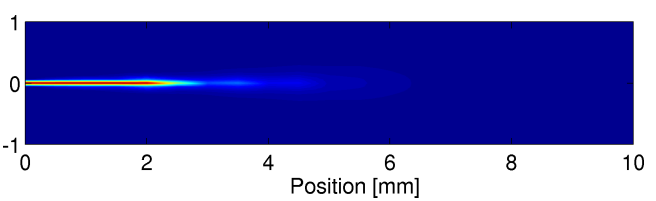

(d) $T=323 \mathrm{~K}$.

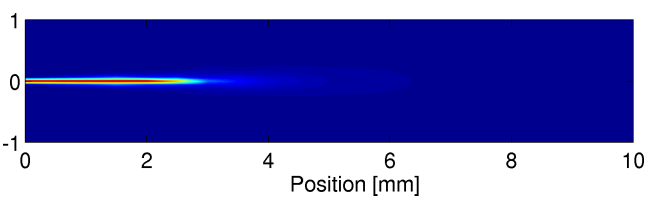

(f) $T=363 \mathrm{~K}$.

Figure 9: Spray near field liquid volume fraction contours at time $0.5 \mathrm{~ms}$ after start of injection for different wall and fuel temperature values.

such as density, do change in a significant amount, but this has no consequences in spray momentum, so neither in spray development (penetration and angle). Nonetheless, consulted literature reports significant influence of the fuel temperature on injector dynamics and other phenomena such cavitation or coking. Thus, fuel temperature is still a parameter to take into consideration for Diesel injection studies even though it does not modify the discharge process and spray development.

It is well known that if the focus of the study is only the spray development, the use of the proposed thermodynamic model may not be needed depending on injection conditions (for example, for low temperature combustion, injected fuel temperature may be significant). However, to accurately simulate nozzle flow and analyze its fluid properties, a thermodynamic model function depending on pressure and temperature is needed. Expansion cooling or fuel heating can be considered in the study, plus the size of the boundary layer can be correctly predicted. This could help to understand the relationship between temperature distribution inside the nozzle and cavitation or coking phenomena. 
R. Payri, J. Gimeno, P. Martí-Aldaraví, M. Alarcón. A new approach to compute temperature in a liquid-gas mixture. Application to study the effect of wall temperature on a Diesel injector, International Journal of Heat and Fluid Flow 68 (2017): 79-86, doi:10.1016/j.ijheatfluidflow.2016.12.008. Author copy

\section{Acknowledgments}

This research was performed in the frame of the project "Estudio de la interacción chorro-pared en condiciones realistas de motor" reference TRA201567679-c2-1-R from Ministerio de Economía y Competitividad (Spanish Ministry of Economy). The equipment used in this work has been partially supported by FEDER Project funds "Dotación de infraestructuras científico téctinas para el Centro Integral de Mejora Energética y Medioambiental de Sistemas de Transporte (CiMeT), (FEDER-ICTS-2012-06)", framed in the operation program of unique scientific and technical infrastructure of the Ministry of Science and Innovation of Spain.

[1] X. Wang, Z. Huang, O. A. Kuti, W. Zhang and K. Nishida, "Experimental and analytical study on biodiesel and diesel spray characteristics under ultra-high injection pressure", International Journal of Heat and Fluid Flow, 31, pp. 659-666, 2010. DOI:10.1016/j.ijheatfluidflow.2010.03.006.

[2] Q. N. Chan, Y. Bao and S. Kook, "Effects of injection pressure on the structural transformation of flash-boiling sprays of gasoline and ethanol in a spark-ignition direct-injection (SIDI) engine", Fuel, 130, pp. 228240, 2014. DOI:10.1016/j.fuel.2014.04.015.

[3] G. Strotos, P. Koukouvinis and A. Theodorakakos, "Transient heating effects in high pressure Diesel injector nozzles", International Journal of Heat and Fluid Flow, 51, pp. 257-267, 2015. DOI:10.1016/j.ijheatfluidflow.2014.10.010.

[4] A. E. Catania, A. Ferrari, M. Manno and E. Spessa, "Thermal Effect Simulation in High-Pressure Injection System Transient Flows", SAE Technical Paper 2004-01-0532, 2004. DOI:10.4271/2004-01-0532.

[5] F. J. Salvador, J. Gimeno, M. Carreres and M. Crialesi-Esposito, "Fuel temperature influence on the performance of a last generation commonrail diesel ballistic injector. Part I: Experimental mass flow rate measurements and discussion", Energy Conversion and Management, 114, pp. 364-375, 2016. DOI:10.1016/j.enconman.2016.02.043.

[6] S. H. Park, H. J. Kim, H. K. Suh and C. S. Lee, "Experimental and numerical analysis of spray-atomization characteristics of biodiesel 
R. Payri, J. Gimeno, P. Martí-Aldaraví, M. Alarcón. A new approach to compute temperature in a liquid-gas mixture. Application to study the effect of wall temperature on a Diesel injector, International Journal of Heat and Fluid Flow 68 (2017): 79-86, doi:10.1016/j.ijheatfluidflow.2016.12.008. Author copy.

fuel in various fuel and ambient temperatures conditions", International Journal of Heat and Fluid Flow, 30, pp. 960-970, 2009. DOI:10.1016/j.ijheatfluidflow.2009.04.003.

[7] R. Payri, F. J. Salvador, J. Gimeno and G. Bracho, "The effect of temperature and pressure on Thermodynamic properties of the Diesel and Biodiesel fuels", Fuel, 90, pp. 1172-1180, 2011. DOI:10.1016/j.fuel.2010.11.015.

[8] A. P. Watkinson and D.I. Wilson, "Chemical Reaction Fouling: A Review", Experimental Thermal and Fluid Science, 14, pp. 361-374, 1997. DOI:10.1016/S0894-1777(96)00138-0.

[9] A. Theodorakakos, N. Mitroglow and M. Gavaises, "Simulation of heating effects in cavitating flows through Diesel fuel injectors caused by extreme fuel pressurization", $8^{\text {th }}$ International Symposium on Cavitation, Singapore, August, 14 $4^{\text {th }}-16^{\text {th }}, 2012$.

[10] A. Vallet, A. A. Burluka and R. Borghi, "Development of an Eulerian model for the "atomization" of a liquid jet", Atomization and Sprays, 11, pp. 619-642, 2001. DOI:10.1615/AtomizSpr.v11.i6.20.

[11] G. Blokkeel, B. Barbeau and R. Borghi, "A 3D Eulerian Model to Improve the Primary Breakup of Atomizing Jet", SAE Technical Paper 2003-01-0005, 2003. DOI:10.4271/2003-01-0005.

[12] J. M. García-Oliver, J. M. Pastor, A. Pandal, N. Trask, E. Baldwin and D. P. Schmidt, "Diesel spray CFD simulations based on the $\Sigma-Y$ Eulerian atomization model", Atomization and Sprays, 23, pp. 71-95, 2013. DOI:10.1615/AtomizSpr.2013007198.

[13] F. J. Salvador, J. Gimeno, J. M. Pastor and P. Martí-Aldaraví, "Effect of turbulence model and inlet boundary condition on the Diesel spray behavior simulated by an Eulerian Spray Atomization (ESA) model", International Journal of Multiphase Flow, 65, pp. 108-116, 2014. DOI:10.1016/j.ijmultiphaseflow.2014.06.003.

[14] J. M. Desantes, R. Payri, J. Gimeno and P. Martí-Aldaraví, "Simulation of the First Millimeters of the Diesel Spray by an Eulerian Spray Atomization Model Applied on ECN Spray A Injector", SAE Technical Paper 20014-01-1418, 2014. DOI:10.4271/2014-01-1418. 
R. Payri, J. Gimeno, P. Martí-Aldaraví, M. Alarcón. A new approach to compute temperature in a liquid-gas mixture. Application to study the effect of wall temperature on a Diesel injector, International Journal of Heat and Fluid Flow 68 (2017): 79-86, doi:10.1016/j.ijheatfluidflow.2016.12.008. Author copy

[15] R. Payri, S. Ruiz, J. Gimeno and P. Martí-Aldaraví, "Verification of a new CFD compressible segregated and multi-phase solver with different flux updates-equations sequences", Applied Mathematical Modelling, 39, pp. 851-861, 2015. DOI:10.1016/j.apm.2014.07.011.

[16] M. Bardi et al., "Engine Combustion Network: comparison of spray development, vaporization, and combustion in different combustion vessels", Atomization and Sprays, 22, pp. 807-842, 2012. DOI:10.1615/AtomizSpr.2013005837.

[17] T. S. Khasanshin, A. P. Shchamiallou and O. G. Poddubskij, "Thermodynamic Properties of Heavy n-Alkanes in the Liquid State: nDodecane", International Journal of Thermophysics, 24, pp. 1277-1289, 2003. DOI:10.1023/A:1026199017598.

[18] A. Kastengren et al., "Engine Combustion Network (ECN): Measurements of Nozzle Geometry and Hydraulic Behavior", Atomization and Sprays, 22, pp. 1011-1052, 2012. DOI:10.1615/AtomizSpr.2013006309.

[19] R. Payri, S. Molina, F. J. Salvador and J. Gimeno, "A study of the relation between nozzle geometry, internal flow and sprays characteristics in Diesel fuel injection systems", KSME International Journal, 18, pp. 1222-1235, 2004.

[20] D. L. Siebers, "Scaling liquid-phase fuel penetration in diesel sprays based on mixing-limited vaporization", SAE Paper 1999-01-0528, 1999. DOI:10.4271/1999-01-0528.

[21] N. Trask, D. P. Schmidt, M. Lightfoot and S. Danczyk, "Compressible modeling of the internal flow in a gas-centered swirl-coaxial fuel injector" Journal of Propulsion and Power, 28, pp. 685-693, 2012. DOI:10.2514/1.B34102.

[22] A. Bondi, "Estimation of Heat Capacity of Liquids", Industrial \&6 Engineering Chemistry Fundamentals, 5, pp. 442-449, 1996. DOI:10.1021/i160020a001.

[23] M. E. Tat and J. H. Van Gerpen, "Measurement of Biodiesel Speed of Sound and Its Impact on Injection Timing", National Renewable Energy Laboratory, Technical Report NREL/SR-510-31262, 2003. 
R. Payri, J. Gimeno, P. Martí-Aldaraví, M. Alarcón. A new approach to compute temperature in a liquid-gas mixture. Application to study the effect of wall temperature on a Diesel injector, International Journal of Heat and Fluid Flow 68 (2017): 79-86, doi:10.1016/j.ijheatfluidflow.2016.12.008. Author copy

[24] Y. A. Çengel and M. A. Boles, Thermodynamics: an engineering approach, McGraw Hill Higher Education, $7^{\text {th }}$ edition, New York, United States of America, 2011.

[25] H. G. Weller, G. Tabor, H. Jasak and C. Fureby, "A tensorial approach to computational continuum mechanics using objectoriented techniques", Computers in Physics, 12, pp. 620-631, 1998. DOI:10.1063/1.168744.

[26] R. Payri, J. Gimeno, P. Martí-Aldaraví and M. Carreres, "Assessment on Internal Nozzle Flow Initialization in Diesel Spray Simulations", SAE Technical Paper 2015-01-0921, 2015. DOI:10.4271/2015-01-0921.

[27] . D. R. Caudwell, J. P. M. Trusler, V. Vesovic and W. A. Wakeham, "The viscosity and density of n-dodecane and n-octadecane at pressures up to $200 \mathrm{MPa}$ and temperatures up to $473 \mathrm{~K}$ ", International Journal of Thermophysics, 25, pp. 1339-1352, 2003. DOI:10.1007/s10765-004-57420 .

[28] L. Pickett, J. Manin, A. Kastengren and C. Powell, "Comparison of Near-Field Structure and Growth of a Diesel Spray Using Light-Based Optical Microscopy and X-Ray Radiography", SAE International Journal of Engines, 7, pp. 1044-1053, 2014. DOI:10.4271/2014-01-1412.

[29] P. Spalart, "Reflections on RANS modelling", Notes on Numerical Fluid Mechanics and Multidisciplinary Design, 111, pp. 7-24, 2010. DOI:10.1007/978-3-642-14168-3-2.

[30] F. J. Salvador, J. Gimeno, M. Carreres and M. Crialesi-Esposito, "Experimental assessment of the fuel heating and the validity of the assumption of adiabatic flow through the internal orifices of a diesel injector", Fuel, 188, pp. 442-451, 2017. DOI:10.1016/j.fuel.2016.10.061.

[31] B. Yu, P. F. Fu, T. Zhang and H. C. Zhou, "The influence of back pressure on the flow discharge coefficients of plain orifice nozzle", International Journal of Heat and Fluid Flow, 44, pp. 509-514, 2013. DOI:10.1016/j.ijheatfluidflow.2013.08.005.

[32] R. Payri, B. Tormos, J. Gimeno and G. Bracho, "The potential of Large Eddy Simulation (LES) code for the modeling of flow in diesel injec- 
R. Payri, J. Gimeno, P. Martí-Aldaraví, M. Alarcón. A new approach to compute temperature in a liquid-gas mixture. Application to study the effect of wall temperature on a Diesel injector, International Journal of Heat and Fluid Flow 68 (2017): 79-86, doi:10.1016/j.ijheatfluidflow.2016.12.008. Author copy

tors", Mathematical and Computer Modelling, 52, pp. 1151-1160, 2010. DOI:10.1016/j.mcm.2010.02.033.

[33] R. Reitz and F. Bracco, "Mechanism of atomization of a liquid jet", Physics of Fluids, 25, pp. 1730-1742, 1982. DOI:10.1063/1.863650.

[34] A. L. Kastengren, F. Z. Tilocco, D. J. Duke, C. F. Powell, X. Zhang and S. Moon, "Time-resolved X-ray radiography of sprays from Engine Combustion Network spray a diesel injectors", Atomization and Sprays, 24, pp. 251-272, 2014. DOI:10.1615/AtomizSpr.2013008642.

[35] R. Payri, F. J. Salvador, J. Gimeno and L. D. Zapata, "Diesel nozzle geometry influence on spray liquid-phase fuel penetration in evaporative conditions", Fuel, 87, pp. 1165-1176, 2008. DOI:10.1016/j.fuel.2007.05.058. 